\title{
Associação de Fungos com Sementes de Espécies Florestais Nativas
}

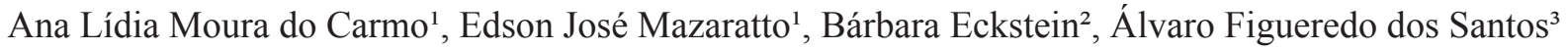

${ }^{1}$ Universidade Federal do Paraná, rua dos Funcionários, 1540, Juvevê, 80035-050, Curitiba, PR, Brasil. ${ }^{2}$ Embrapa Recursos Genéticos e Biotecnologia - Parque Estação Biológica, 70770-901, Brasília, DF, Brasil. ${ }^{3}$ Embrapa Florestas, Guaraituba, Estrada da Ribeira, km 111, 83411000, Colombo, PR, Brasil.

Autor para correspondência: Álvaro Figueredo dos Santos (alvaro.santos@embrapa.br)

Data de chegada: 05/07/2016. Aceito para publicação em: 17/04/2017.

$10.1590 / 0100-5405 / 2211$

\section{RESUMO}

Carmo, A.L.M.; Mazaratto, E.J.; Eckstein, B.; Santos, A.F. Associação de Fungos com Sementes de Espécies Florestais Nativas. Summa Phytopathologica, v.43, n.3, p.246-247, 2017.

No Brasil, ainda há poucas pesquisas sobre os microrganismos associados às sementes florestais. O objetivo desse trabalho foi detectar fungos associados às sementes de seis espécies florestais nativas: açoita-cavalo (Luehea divaricata), araçá amarelo (Psidium cattleyanum), corticeira (Erythrina falcata), rabode-bugio (Lonchocarpus sp.), vassoura-vermelha (Dodonea viscosa) e paujacaré (Piptadenia gonoacantha). Foram identificados oito gêneros de fungos potencialmente patogênicos: Cladosporyum sp., Fusarium sp., Pestalotiopsis sp., Phomopsis sp., Coletotrichum sp., Alternaria sp., Phoma sp. e Botrytis sp. e fungos saprófitas: Aspergillus sp., Penicillium sp., Rhizopus sp., Epicoccum sp., Torula sp., Trichoderma sp., Gliocladium sp., Chaetomium sp. e Trichothecium sp. Os resultados evidenciam a diversidade de fungos associados às sementes florestais nativas, incluindo vários potencialmente fitopatogênicos.

Palavras-chave: Patologia de sementes; qualidade sanitária; espécies nativas.

\begin{abstract}
Carmo, A.L.M.; Mazaratto, E.J.; Eckstein, B.; Santos, A.F. Association of Fungi with Seeds of Native Forest Species. Summa Phytopathologica, v.43, n.3, p.246-247, 2017.

In Brazil, there is still scarce research on microorganisms associated with forest seeds. The aim of this study was to detect fungi associated with seeds of six native forest species: "açoita-cavalo" (Luehea divaricata), "araçá amarelo" (Psidium cattleyanum), "corticeira" (Erythrina falcata), "rabo-de-bugio" (Lonchocarpus sp.), "vassoura-vermelha" (Dodonea viscosa) and "pau-jacaré" (Piptadenia gonoacantha). Eight genera of fungi were identified as potentially

pathogenic: Cladosporyum sp., Fusarium sp., Pestalotiopsis sp., Phomopsis sp., Coletotrichum sp., Alternaria sp., Phoma sp. and Botrytis sp., and saprophytic fungi: Aspergillus sp., Penicillium sp., Rhizopus sp., Epicoccum sp., Torula sp., Trichoderma sp., Gliocladium sp., Chaetomium sp. and Trichothecium sp. Results evidence the diversity of fungi associated with native forest seeds, including several potentially phytopathogenic fungi.
\end{abstract}

Keywords: Seed pathology; sanitary quality; native species.

Espécies nativas possuem grande relevância ecológica, devido ao potencial em reflorestamento e recomposição de áreas degradadas. No entanto, muitas espécies com destaque pela qualidade da madeira, uso medicinal, ornamental e industrial, acabam sendo dizimadas pelo desmatamento e cultivos agrícolas (12). Algumas espécies florestais como açoita-cavalo (Luehea divaricata Mart.) araçá amarelo (Psidium cattleyanum Sabine L.), corticeira (Erythrina falcata Benth.), rabode-bugio (Lonchocarpus sp. Mart. ex Benth.), vassoura-vermelha (Dodonea viscosa Jacq.) e pau-jacaré (Piptadenia gonoacantha [Mart.] J.F.Macbr.) apresentam diferentes finalidades comerciais, no entanto, poucas informações estão disponíveis quanto à qualidade sanitária de sementes dessas espécies (3). Além disso, as sementes florestais nativas têm uma oferta reduzida que depende da espécie, do ano e do indivíduo (10), dificultando a execução de trabalhos de pesquisa nesta área.

A demanda por sementes de espécies florestais nativas tem aumentado nos últimos anos, principalmente para atender a lei $n^{\circ} 12.651$ (2) que dispõe sobre a proteção da vegetação nativa no Brasil, as quais englobam também as áreas de preservação permanente e reserva legal. Com o aumento do intercâmbio de sementes entre regiões, aumenta-se também o risco de transporte de fitopatógenos associados às sementes, representando uma forma de disseminação de patógenos para novas áreas (3). Em algumas espécies nativas, alguns autores já mostraram a associação de fungos (11); no entanto, desconhece-se estas informações para várias outras espécies, incluindo as espécies araçá amarelo, corticeira, rabo-de-bugio, vassoura-vermelha e pau-jacaré.

O conhecimento da sanidade das sementes é importante, pois minimiza os riscos de perdas na produção de mudas, bem como o transporte de sementes contaminadas por fitopatógenos para novas áreas. Face ao exposto, o objetivo deste trabalho foi detectar fungos em sementes de seis espécies florestais nativas da Mata Atlântica.

As seis espécies florestais nativas usadas no trabalho foram: açoitacavalo, araçá amarelo, corticeira, rabo-de-bugio, vassoura-vermelha e pau-jacaré. Para detecção dos fungos empregou-se o método do papel filtro (PF), no qual foram distribuídas 200 sementes de cada espécie, equidistantemente, em caixas gerbox, contendo papel filtro esterilizado umedecido com água destilada esterilizada. A incubação foi conduzida em condições de temperatura e fotoperíodo controlados de $20^{\circ} \mathrm{C}$ e $12 \mathrm{~h} / 12 \mathrm{~h}$ (luz/escuro), respectivamente (11). Após o período de sete dias de incubação, os fungos foram identificados de acordo com suas características morfológicas.

Pelo teste PF encontrou-se 17 gêneros de fungos associados às sementes das seis espécies florestais nativas (Tabela 1). Essa diversidade de fungos chama a atenção para a forma de coleta que, na maioria das vezes, é realizada pela coleta de sementes caídas no solo e que, portanto, 
Tabela 1. Incidência de fungos (\%) em lotes de sementes de seis espécies florestais nativas.

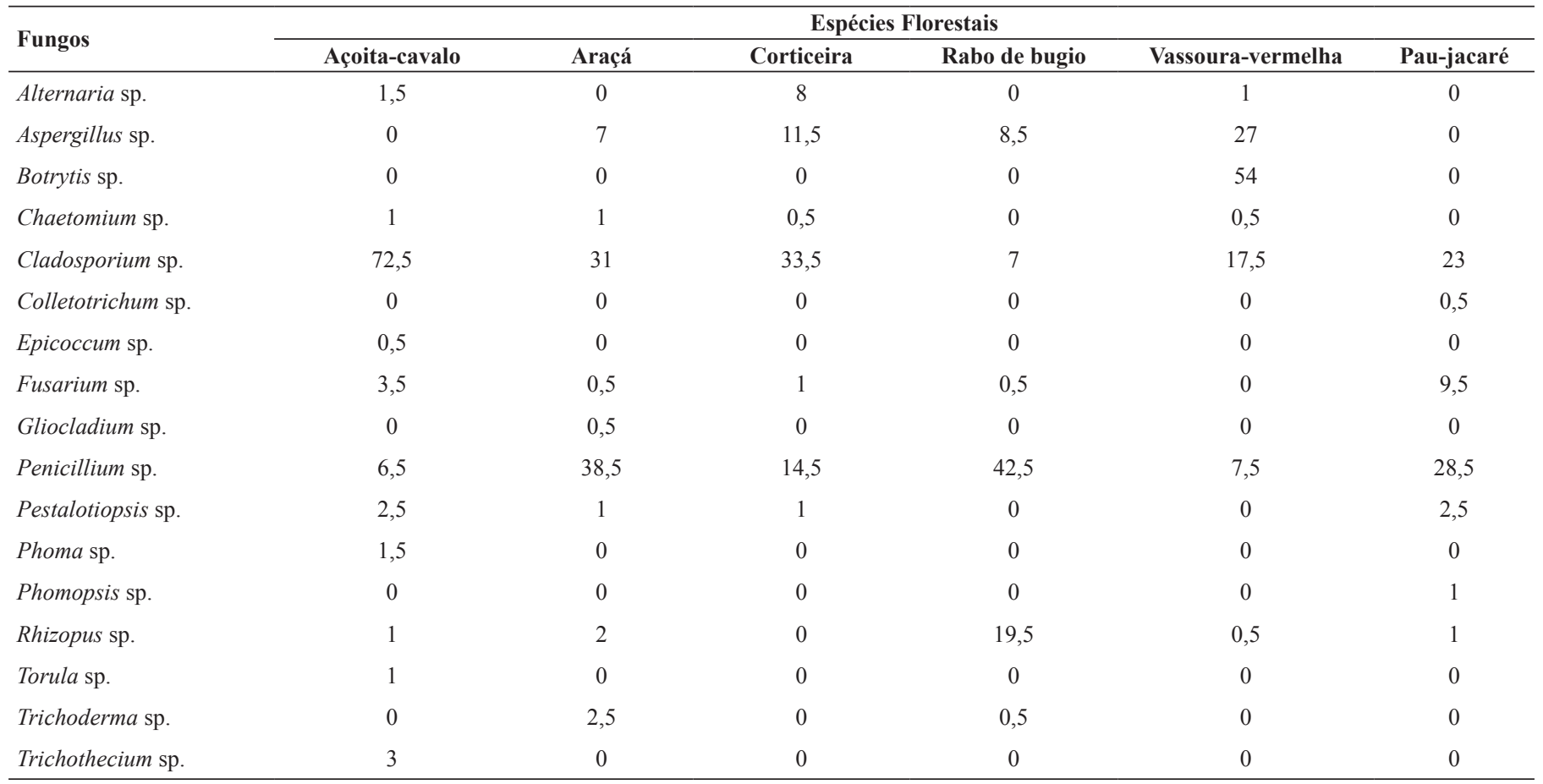

aumenta a chance de contaminação por microrganismos de solo, assim como cuidados durante a fase de beneficiamento.

Neste trabalho, Fusarium spp. foi encontrado nas sementes de cinco espécies florestais nativas (açoita-cavalo, araçá, corticeira, rabo-debugio e pau-jacaré). Este fungo tem sido associado com tombamentos em pré e pós emergência de várias espécies florestais $(5,7,8)$. No entanto, desconhece-se a sua associação com as espécies florestais trabalhadas nesse trabalho, com exceção de açoita-cavalo que Maciel et al. (9) que verificaram a presença de Fusarium sp..

Cladosporium sp. foi o fungo mais comumente encontrado neste trabalho, chegando a 72,5\% nas sementes de açoita-cavalo. O fungo Botrytis sp. também apresentou alta incidência em sementes de vassoura vermelha (54\%), porém não foi observado nas outras espécies florestais. Estes fungos geralmente causam manchas foliares em mudas de várias espécies florestais acarretando em perda da qualidade da muda e, consequentemente, prejuízos na produção (1).

Outros fungos potencialmente fitopatogênicos encontrados neste trabalho foram Pestalotiopsis sp., Phomopsis sp., Colletotrichum sp., Alternaria sp. e Phoma sp., com percentuais de incidência variando de $0,5 \%$ a $8 \%$. Destaca-se o fungo Colletotrichum sp., o qual já foi relatado a associação em outras espécies florestais nativas como Araucaria angustifolia, Bactris gasipaes, Euterpe edulis e Ocotea porosa (11). No entanto, para pau-jacaré, estudada neste trabalho, constitui-se no primeiro relato de Colletotrichum sp. Esse fungo causa lesões no cotilédone e manchas foliares e já foi detectado em sementes de paineira (6). Esse patógeno causa a doença conhecida como antracnose em vários hospedeiros agrícolas e florestais. Causam lesões nos frutos que acabam sendo porta de entrada para fungos oportunistas e insetos podendo acarretar na morte da planta, além de reduzir a produtividade (4).

O presente trabalho mostra que sementes florestais nativas podem ser veículo de disseminação de fungos potencialmente fitopatogênicos, tais como: Pestalotiopsis sp., Botrytis sp., Colletotrichum sp., Phoma sp., Phomopsis sp., Alternaria sp., e Fusarium sp., aumentando o conhecimento sobre o número de espécies florestais nativas da Mata Atlântica que podem disseminar fungos. Dessa forma, a demanda cada vez maior de sementes florestais nativas, justifica a necessidade de estudos visando elucidar a importância desses fungos nas sementes e mudas.

\section{REFERÊNCIAS}

1. Alfenas, A.C.; Zauza, E.A.V.; Mafia, R.G.; Assis, T.F. Clonagem e doenças do eucalipto. Viçosa: UFV. 2004. 442p.

2. Brasil. Lei $n^{\circ} 12.651$, de 25 de maio de 2012. Diário Oficial da União, Brasília, DF, 25 maio 2012.

3. Carneiro, J.S. Qualidade sanitária de sementes de espécies florestais em Paraopeba, MG. Fitopatologia Brasileira, Brasília, v.15, p.75-76, 1990.

4. Cunha, M.M.; Santos Filho, H.P.; Nascimento, A.S. do. Manga. Fitossanidade. Brasília: Embrapa mandioca e fruticultura, Cruz das Almas-BA. Brasília - Embrapa comunicação para transferência de tecnologia, frutas do Brasil, 2000.

5. Lazarotto, M.; Muniz, M.F.B.; Beltrame, R.; Santos, A.F.; Maciel, C.G.; Longhi, S.J. Sanidade, transmissão via semente e patogenicidade de fungos em sementes de Cedrela fissilis procedentes da região sul do Brasil. Ciência Florestal, Santa Maria, v.22, n.3, p.493-503, 2012.

6. Lazarotto, M.; Muniz, M.F.B.; Santos, A.F. dos. Detecção, transmissão, patogenicidade e controle químico de fungos em sementes de paineira (Ceiba speciosa). Summa Phytopathologica, Botucatu, v.36, n.2, p.134-139, 2010.

7. Lorenzi, H. Árvores brasileiras: manual de identificação e cultivo de plantas arbóreas nativas do Brasil. 5.ed. Nova Odessa. Instituto Plantarum de Estudos da Flora, 2008. v.1, 384p.

8. Maciel, C.G.; Muniz, M.F.B.; Santos, A.F.; Lazarotto, M. Detecção, transmissão e patogenicidade de fungos em sementes de angico-vermelho (Parapiptadenia rígida). Summa Phytopathologica, Botucatu, v.38, n.4, p.323-328, 2012.

9. Maciel, C.G.; Souza, L.B.; Bovolini, M.P.; Brum, D.L.; Muniz, M.F.B.; Buriol, G.A. Qualidade físiológica e sanitária de sementes de açoita-cavalo (Luehea divaricata). Pesquisa Florestal Brasileira, Colombo, v.33, n.75, p.331-338, 2013.

10. Nogueira, A.C.; Medeiros, A.C.S. Coleta de sementes florestais nativas. Colombo: Embrapa Florestas, 2007. (Circular, 144).

11. Santos, A.F.; Parisi, J.J.D.; Menten, J.O.M. (Ed.). Patologia de sementes florestais. Colombo: Embrapa Florestas, 2011. 236p.

12. Sarmento, M.B.; Villela, F.A. Sementes de espécies florestais nativas do sul do Brasil. Informativo ABRATES, Londrina, v.20, n.1/2, p.39-44, 2010. 